\title{
Incentivizing Collaborative Learning through Visual Feedback about Conflict in Wiki
}

\author{
Kewen $\mathrm{Wu}^{1,2}$, Julita Vassileva ${ }^{2}$, Qinghua $\mathrm{Zhu}^{1}$ \\ 1. School of Information Management, Nanjing University \\ Nanjing, China \\ Email: kewen-wu@163.com, qhzhu@nju.edu.cn \\ 2. Department of Computer Science, University of Saskatchewan \\ Saskatoon, Canada \\ Email: jiv@cs.usask.ca
}

\begin{abstract}
Conflict emerging from collaboration in wiki can be helpful to achieve a better quality of collaborative learning. However, few studies have utilized conflict to support collaborative learning and wiki systems themselves have limitations. This paper proposes to provide visual feedback about conflict in wiki based on the "page history" to create a sense of audience, psychological ownership and support information seeking. Theoretical model is built upon literature, and the Partial Least Squares (PLS) results from a survey study (208 responses) indicate that conflict awareness can motivate students to participate, achieve better conflict resolution and improve the quality of learning. The results also show that the new design is well accepted by students and can significantly enhance the influence of conflict awareness on participation and conflict resolution.
\end{abstract}

Keywords- collaborative learning; wiki; conflict; design; virtual collaboration

\section{INTRODUCTION}

Wiki is a kind of open system which allows everyone to collaboratively contribute content. When such open systems are implemented on the Internet, they usually have the following characteristics [1-4]:

- The number of participants is large, ranging from dozens to tens of thousands or more, and the group size is unstable due to high rate of the membership turnover.

- Mostly unpaid, voluntary and self-organized contribution. The amount of contributions usually follows a long-tail distribution.

- Participants interact on a many-to-many basis via virtual media as opposed to a one-to-one basis (e.g., instant messaging), or a one-to-many basis (e.g., mail listing servers)

- Participants collectively create new content (e.g., text, software) to build long-lasting artifacts which have a possible value to the larger unknown audience.

A prime example of wiki implementations is Wikipedia, the largest online encyclopedia. Wikipedia's English version contains words over 50 times as many as Encyclopedia

This research is supported by the Chinese Social Science Foundation (10ATQ004), the Graduate Student Innovation Project of Jiangsu, China under contract No. CX10B 022R. And the program for outstanding PhD candidate of Nanjing University
Britannica, with a similar rate of serious errors [5]. However, behind the sparkling success of Wikipedia, wiki systems are suffering from high coordination cost (e.g. back and forth editing) [6-8], reflecting intense conflict among participants in collaboration. According to statistics about Wikipedia, more than $6.7 \%$ of the edits goes to restoring other participants' work to previous versions [8], influencing about $34.6 \%$ of the edits [1], and such kind of maintenance work will continue grow [9].

While wiki technology forms a new model of virtual collaboration (named massive virtual collaboration) [4] and is extensively used as a knowledge management tool in various types of organizations [10], it enables us a new chance to support collaborative learning activities. Many studies have addressed the feasibility of using wiki system as a powerful tool in collaborative learning, and the results show that this kind of technology can increase collaboration activities among students, facilitate knowledge creation and sharing [11, 12], provide dynamic repositories that allow students to learn by constructing knowledge based on their own experience in a self-directing way [13], and develop a sense of community [13, 14], etc.

However, several points have also been figured out, which may influence the success of wiki implementations in collaborative learning environments. While other issues, like class sizes, external awards and culture differences [12, 15], cannot be easily altered in real settings, and problems like "do not know how to use" [12] can be eased by training, the sense of audience (knowing intuitively that that the voice and opinions have listeners) is considered as a critical element to motivate contribution [16]. Without a sense of audience, students may not be willing to contribute or will just contribute lots of very low quality content without interacting with each other. Furthermore, critics have also stated that such collaborative writing platforms (e.g. Wikipedia, Google Doc) cannot handle psychological ownership well and cannot facilitate generation of content trust and knowledge exchange related to the tracking of page logs, which are harmful to the collaboration efficiency and retaining participants (e.g. [17-20])

In order to solve the issues mentioned above, this study raises a critical question: how to utilize conflict to facilitate collaborative learning in wiki systems? 
In this paper, first, visual feedback functions about conflict based on "page history" logs are designed to help the students build up the sense of audience and psychological ownership, motivate them to contribute and facilitate collaboration in wiki. Being an extension of the authors' previous work [21], the design in this study incorporates visualization of conflict network, in order to make the hidden conflict relationship more obvious. Second, Robey's model of conflict [22] is partially modified and is used to explain how important factors (participation, personal influence, conflict resolution, conflict awareness) related to collaborative learning process interact to quality of collaborative learning (e.g. efficiency, quality of artifact). And third, comparative group study is considered in the model so as to reflect the usefulness of new design.

This paper is organized as follows. Limitations of "page history" tool in current wiki systems are introduced in section 2 , and related studies are reviewed in section 3. Research hypothesis is put forward in section 4. Details about design are introduced in section 5. Research method is presented in section 6 . The test of hypothesis is conducted by using surveybased Partial Least Squares (PLS) analysis (section 7). Conclusion of the result and implications are discussed in section 8 .

\section{Problem Statement}

In original wiki systems, the "page history" tool is the only entrance to track the whole revisions of current page and display the differences between two selected revisions. However, this function cannot meet user's needs in many cases. For example,

Case 1: Content trust issue $[18,20]$. When a reader wants to read or use specific piece of information in an article, what he/she values most is the quality of information, especially when the content is not as similar as he/she expected or the information quality cannot be judged by the reader himself alone. Wiki only shows the latest version of the article to the reader, and it does not offer any information about the evolution or the trustworthiness of the content. If the reader could know the changes of the content, showing that the subsequent edits just enriched the content, rather than modified the opinions back and forth, he/she might perceive high information quality about the content.

Case 2: Knowledge exchange issue. When a contributor who wishes to improve the quality of the article and discuss with others, he/she may be eager to know the whole changes of public opinions related to the content, and if necessary, he/she may also want to know who hold these opinions and make further discussion with them.

Case 3: Psychological ownership issue [23]. When a contributor uploads content to the whole community for the purpose of sharing his own ideas/opinions and building sense of audience, he/she may be motivated to know how much content still belongs to him/her after many times of editing by others. Sometimes, one may be very sensitive about the changes of content ownership [19].

In the above three cases, the only way to check the quality (case 1), find various opinions (case 2) and identify the ownership (case 3) is to use the "page history" tool to track modifications (debate among previous contributors) from relevant revisions. However, this progress is usually very harsh since the user does not know which revisions contain modifications on the specific pieces of content. The user needs to compare every two revisions to locate the modifications, which is very time-consuming and uncomfortable when there are too many versions and paragraphs (imagining that the user compares every two revisions where there are thousands of revisions).

Take Fig. 1 for example, when a user wants to see the history of the specific paragraph in an article and discuss with corresponding editors, he/she should use the "page history" tool to compare every two revisions in the whole revision list. Suppose there are 12 revisions in the list and only 2 revisions (No.6 and No.11) are relevant to the paragraph, while other revisions are irrelevant (but the user does not know). In an extreme case, the user should compare 66 times of comparisons to find out the right revisions, and the success rate is $3.03 \%$. In regular usage, most users will give up in locating relevant revisions in "page history" since the success rate is too low. As a result, the needs of checking the quality (case 1), finding various opinions (case 2) and identification of ownership cannot be fulfilled.

\section{LITERATURE REVIEW}

The phenomenon of conflict has been noticed by educational researchers for many years. The themes of this research limit the literature review to collaborative learning, especially computer-supported collaborative learning (CSCL). Since the knowledge exchange process of CSCL is almost the same as collaborative work in organizations, relevant organizational studies are taken into consideration as well.

\section{A. Conflict categorization and conflict in wiki}

Conflict itself has many definitions. One kind of definition treats conflict as a kind of "awareness", that it is an awareness on the part of the parties who involve in discrepancies, incompatible wishes or irreconcilable desires [24]. While other definitions view conflict as an "event", which is the

\section{RKO Pictures}

From Wikipedia, the free encyclopedia

RKO (Radio-Keith-Orpheum) Pictures was an American film production and distribution company. As RKO Radio ig Five studios of Hollywood's Golden Age. The business was formed after the Keith-Albee-Orpheum (KAO) theater Film Booking Offices of America (FBO) studio were brought together under the control of the Radio Corporation of An

\section{RKO Pictures: Revision history}

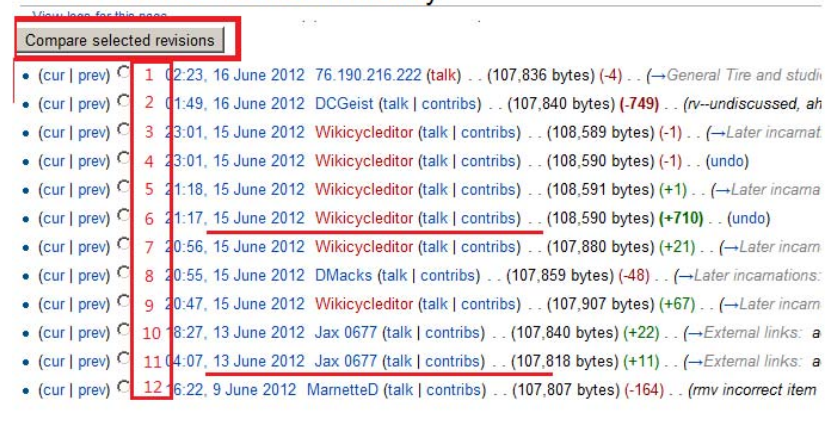

Figure 1. Example of wiki "page history" 
interference by one individual or group in the attempts by another individual or group to achieve a goal [25]. No matter which kind of definition, conflict shows the differences on opinions or goals among parties involved. Prior organizational studies have identified three types of conflict: relationship, task, and process conflict [26]. Relationship conflict refers to the disagreement based on personal and social issues. Task conflict is void of the intense interpersonal negative emotions that are usually linked with relationship conflict, rather, it is only related to conflict about ideas and differences of opinions about the task. Process conflict refers to disagreement over the group's approach to the task, its methods, and its group process [26]. Although relationship conflict and process conflict are harmful to group performance (e.g. collaboration efficiency and quality of artifact), task conflict is found to be beneficial since it encourages diversity of opinions [27]. However, harsh task conflict may trigger relationship conflict and thus undermine group performance [28].

In wiki systems, conflicts among opinions are inherent to the collaborative process [29]. Everyone has the same rights to edit others' content (except the administrators), to make decision on whether certain pieces of text, hyperlink (interpage and external resources) or images should be included in the articles or not, and how the structure of articles should be organized. Each user faces the risk that the information he/she contributed, whether good or bad, would be edited or deleted by others, with the latest changes immediately visible to subsequent visitors [8]. Since each version of the article has been confirmed by the corresponding editor before submission, conflict thus manifests itself through editing or deleting activities showing latent disagreement among users involved, implying incompatible goals or interests [30]. Conflict in wiki pages is more likely to be task oriented conflict. Most of the time, users do not know each other, they modify others' contributions only because there is something improper, not due to the hostile relationship existing between these two persons [1]. And a content analysis on Wikipedia talk pages suggests that most common arguments are about what information should be included and how the structure of the content should be organized [31].

The majority of organizational studies on conflict are conducted in classic group/virtual collaboration context, however, wikis have distinct characteristics such as selforganized voluntary participation and many-to-many communication mechanism that differ from classic collaboration [2, 29]. A study on information quality in Wikipedia has found that task conflict can lead to higher quality of articles [29]. However, there is no finding in other wiki implantations (e.g. CSCL), thus extant theoretical framework need to be further investigated in different wiki contexts.

Extent studies on visualization conflict (or "page history") in wiki have at least two limitations. First, many visualization tools are used for descriptive analysis (e.g. [32]), not for utilizing conflict during collaboration. Second, the information provided by the visualization tool is not rich enough. For example, a history flow visualization tool designed in [33] can only reflect the changes of the whole article, and cannot solve all the issues mentioned in section 2. The same problem also happens in [34], which uses chromo grams to reflect different edit actions in time series. And a history tree visualization tool designed in [35] can give users detailed information about the content evolution, however, it can only partially solve knowledge exchange issue (case 2 in section 2) since it points out the users who hold different views. An embedded tool designed in [34] can give page-level statistics information, such as a pie chart which shows the proportion of each editor's contributions. It can partially solve authorship issue (case 3 in section 2) since it shows the overall influence of each editor, but it cannot tell users when, where and how the content is changed.

\section{B. Robey's model of conflict}

Robey published several papers between 1983 and 1993 to build up a comprehensive model of conflict in organizational context $[22,36]$. In this model, relationships among five constructs are established, that participation has positive effects on influence and project success; influence has positive effects on conflict, conflict resolution and project success; conflict negatively influences conflict resolution and project success; and conflict resolution positively influence project success.

The model has been confirmed in some information system development studies. However, few studies have tested the model in other contexts (e.g. CSCL). Furthermore, this model does not distinguish types of conflict but only evaluate the consequences of general conflict. Thus, the model needs to be refined and tested in different contexts.

In this study, two modifications are introduced in Robey's model. These are, first, "conflict" in the original model is replaced by "conflict awareness", in order to avoid potential misunderstanding due to different definitions of conflict (mentioned previously). Second, the scope of conflict is limited to task conflict due to the characteristics of wiki and research setting (e.g. anonymity; only content contribution, no maintenance work).

\section{Conflict in collaborative learning studies}

It has been pointed out that the adoption of CSCL should take conflict into consideration because current meanings attached to collaboration are too positive, resulting CSCL slowly adopted [37]. However, few studies on collaborative learning can be found to investigate the influences of conflict. Exceptions like: a study conducted by [38] shows that interpersonal conflict is positive associated with learning, however, the reason why this result is opposite to previous studies is probably because the anonymity of communication in the study enable students to insult each other with lower interpersonal cost. Another study on project-based collaborative learning finds that conflict emerges with a variety of reasons (e.g. poor communication, task management, lack of responsibility), and it will undermine performance [39].

Besides lacking of studies on evaluating consequences of conflict, almost no studies can be found to utilize conflict to promote collaborative learning. Thus, conflict and its influences, as well as how to cope with conflict are needed for further attention. 


\section{RESEARCH HYPOTHESIS}

In CSCL context, participation is defined as the extent to which students are engaged in activities related to the learning process, including activities that are aimed at preparing and contributing to the learning project. Personal influence is defined as the extent to which students affect the final output of the learning process. Conflict awareness is defined as the extent to which students feel the degree of intensity about the conflict occurring during knowledge exchange. Conflict resolution refers to the extent to which the conflict arguments are replaced by agreement and consensus. And group performance, which is the main reflection of learning achievements, is defined as the attainment of group goals, including the quality of artifacts and efficiency of the collaboration. The definitions of above mentioned variables are in agreement with previous related studies $[22,29,36]$.

Student's participation is positively associated with personal influence, since personal influence can only be exerted after participation [22]. Clearly, the more opinions a student shares, the higher personal influence he/she receives from other students. In a virtual environment, the successful functioning of a virtual community is impossible without an active participation of a substantial part of its members [40]. Without active participation, there will not be enough materials (or opinions) either for sharing or for conducting activities aiming at building group artifacts. In previous information system studies, positive relationships between participation and influence, as well as participation and group performance have been supported [36].
H1: Participation will have a positive effect on personal influence

H2: Participation will have a positive effect on group performance

Students may not know each other's opinions and interests without the exercise of personal influence. Under the impact of personal influence, consensus or compromise can be achieved more efficiently and constructive resolution of conflict can be put forward [22]. Personal influence reflects social power and leadership within the group, which are often found to positive influence group performance [41]. Moreover, results from previous studies have supported that personal influence positively affect conflict resolution and group performance [22]

H3: Personal influence will have a positive effect on conflict resolution

H4: Personal influence will have a positive effect on group performance

Unsolved conflict issues are usually found to be detrimental to the successful completion of the task [22]. Conflict resolution is beneficial for students since group norms and communication skills are enhanced when gaining conflict resolution. And the knowledge of each student is increased by looking at the group artifacts after the group decision about the conflict issue has been made. Robey's study has found the positive relationship between conflict resolution and group performance [22].

H5: Conflict resolution will have a positive effect on group

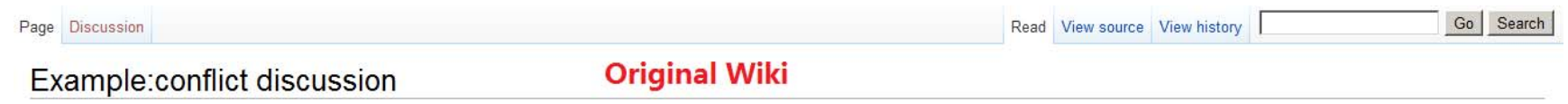

Conflict is defined as an awareness on the part of the parties involved of discrepancies, incompatible wishes or irreconcilable desires. Prior studies have identified three types of conflict: relationship, task, and process conflict. Task conflict is found to be beneficial since it encourages diversity of opinions. However, harsh task conflict may trigger relationship conflict and thus undermine group performance.Relationship conflict and process conflict are harmful to group performance (e.g. collaboration efficiency and quality of artifact).

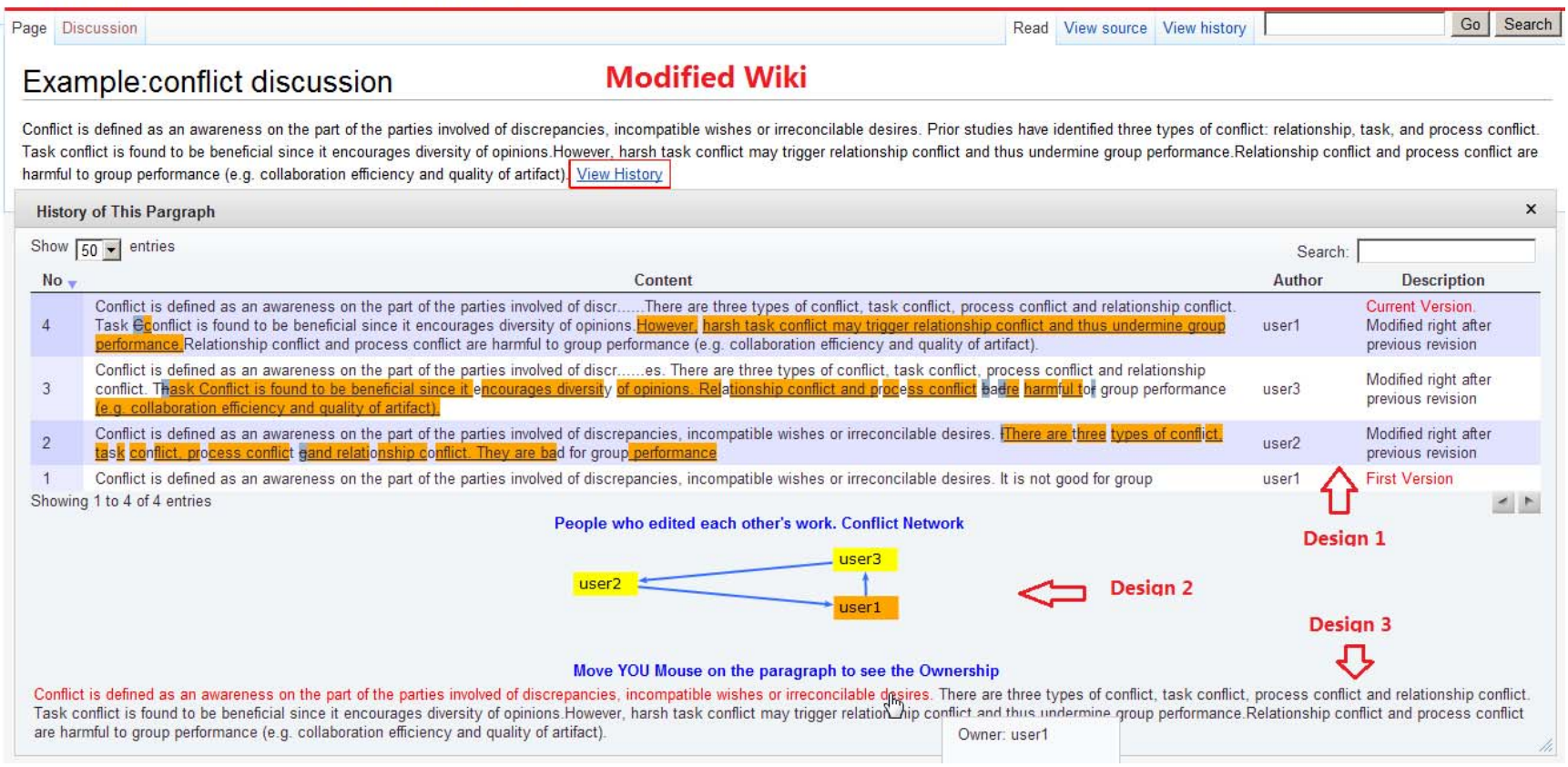

Figure 2. the original wiki and modified wiki in this study 
performance

Discussion (task conflict) among students can generate more ideas and yield better performance [27], moreover, studies suggest that making social norms visible can increase the participant's social behaviors[42]. Meanwhile, cognitive dissonance theory proposes that people have a motivational drive to reduce cognitive dissonance (a discomfort caused by holding conflicting ideas simultaneously) [43]. Therefore, making conflict events visible can make student aware of conflict and incentivize them to participate, since the awareness of conflicting ideas will cause one's discomfort feeling and drive him/her to solve the problem. At the same time, associated information can help students to find the solution to the conflict (e.g. find the most arguable point quickly) and achieve better performance.

H6: Conflict awareness will have a positive effect on participation

H7: Conflict awareness will have a positive effect on conflict resolution

H8: Conflict awareness will have a positive effect on group performance

However, due to different levels of conflict visibility that the original wiki system and modified wiki system (new design in this paper) give, the degree of awareness may be vary when students facing conflict event. When the level of conflict visibility is high, the students can quickly notice the conflict event and know the arguable points, which will lead to more participative activities, effective achievement of resolution and good performance.

H9: The new design will increase the positive effect of conflict awareness on participation, conflict resolution and group performance.

\section{DESIGN OF VISUAL FEEDBACK ABOUT CONFLICT}

The new design in this study is based on four assumptions. First, by providing paragraph-based revision history, the user can focus on the specific part of content and reduce the time and effort spend on locating relevant revisions from a huge list of revisions; second, by providing complete edit history of the content, the user can know exactly the evolution of opinions and corresponding editors to communicate with; third, by providing visualization of edit relationships among editors, the user can know the inner interpersonal structures (conflict network) behind the editing of content; and forth, by providing word-based text-ownership, the user can know the personal influence inside the community and be motivated to contribute in order to enlarge his/her influence.

There are three functions in the new design, which is implemented by using PHP, JAVA-based web service, Lucene and jQuery. The design is performed as an embedded tool in the main page of each article, which would save users' time and efforts spent on switching pages between the "page" tab and "page history" tab (see Fig. 2).

As it is shown in Fig. 2, when a user moves the mouse over a paragraph, a hyperlink named "View History" will be displayed. A dialog will be triggered after the hyperlink is clicked. There are three functions jointly shown in this dialog, which are described as follows:

The first function (design 1) is paragraph-based revision history, and it highlights the added/deleted content between every former revision and later revision (the revisions can be sorted in ascending and descending orders). It also shows information about corresponding editors to facilitate further communication (click the name of editor will trigger the navigation to the editor's talk page) and shows the degree of conflict (popularity) of this paragraph. Moreover, in order to avoid displaying a long list of tiny and useless edits, the revisions can be hided or displayed by detecting whether the size of changes reaches a specific threshold.

The second function (design 2) is visualization of conflict network of this paragraph. Each node is represented as an editor and each directed edge shows that the content of the editor on arrow side has been modified/deleted by the other editor. The thickness of each edge is decided by the amount of conflict existed between the two nodes (editors). Note that if an editor just adds content without modifying others' content, there would be no conflict. Click the node will trigger the navigation to the corresponding editor's talk page.

The third function (design 3) is word-based text ownership. When the user moves the mouse over the words, it will show the author of the words.

\section{RESEARCH METHOD}

The lab experiment consists of two steps: survey study and descriptive analysis of usage logs.

In survey study (see Fig. 3), all participants were required to do three rounds of discussion (each round lasts about 7 days, followed by a 7-day break). And in each round, the whole group was randomly divided into two sub-groups with almost equal size, namely controlled group (use original wiki) and experimental group (use modified wiki). Before the discussion started, there was a 10 minutes speech to make the participants fully understand how to use the wiki system. The definition of conflict is further introduced in another 10 minutes speech to help the students distinguish different types of conflict, since this study only focuses on task conflict.

The participation was anonymous, which could reduce the probability of generating relationship conflict. No maintenance work on policies is necessary since the participants could not change the policies in wiki, thus reducing generation of process conflict.

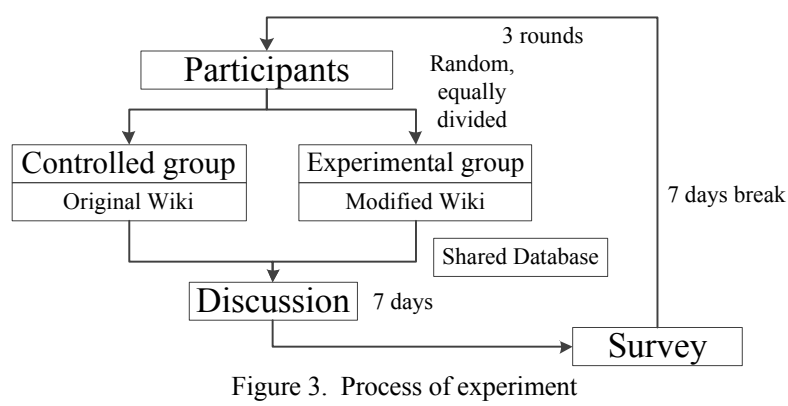

Figure 3. Process of experiment 
TABLE I. DETAILS ABOUT QUESTIONNAIRES

\begin{tabular}{|c|c|c|}
\hline Constructs & ID & Description \\
\hline \multirow{4}{*}{$\begin{array}{l}\text { Conflict } \\
\text { Awareness }\end{array}$} & CA1 & $\begin{array}{l}\text { During collaboration, how much conflict did you } \\
\text { feel among students? }\end{array}$ \\
\hline & $\mathrm{CA} 2$ & $\begin{array}{l}\text { To what extent were any issues debated among } \\
\text { other students and yourself? }\end{array}$ \\
\hline & CA3 & $\begin{array}{l}\text { How much disagreement on opinions were you } \\
\text { directly involved in? }\end{array}$ \\
\hline & CA4 & $\begin{array}{l}\text { How soon did the student who holds conflicting } \\
\text { opinions respond to you (in any way)? }\end{array}$ \\
\hline \multirow{3}{*}{ Participation } & PA1 & $\begin{array}{l}\text { What would you estimate was the amount of time } \\
\text { spent by you in preparing for this topic? }\end{array}$ \\
\hline & PA2 & $\begin{array}{l}\text { How much content did you contribute comparing to } \\
\text { others? }\end{array}$ \\
\hline & PA3 & $\begin{array}{l}\text { How frequently was your content contributions } \\
\text { (add, edit, delete) in Wiki system for this topic? }\end{array}$ \\
\hline \multirow{4}{*}{$\begin{array}{l}\text { Personal } \\
\text { Influence }\end{array}$} & IN1 & $\begin{array}{l}\text { How would you assess your influence over the } \\
\text { collaboration with others? }\end{array}$ \\
\hline & IN2 & How successful were you in asserting your opinion? \\
\hline & IN3 & $\begin{array}{l}\text { To what extent were you able to have your opinions } \\
\text { actually considered by others? }\end{array}$ \\
\hline & IN4 & $\begin{array}{l}\text { Overall, how would you rate your personal } \\
\text { influence? }\end{array}$ \\
\hline \multirow{3}{*}{$\begin{array}{l}\text { Conflict } \\
\text { Resolution }\end{array}$} & RE1 & $\begin{array}{l}\text { To what extent were differences of opinions } \\
\text { resolved to satisfy all students involved in the } \\
\text { conflict issues? }\end{array}$ \\
\hline & RE2 & $\begin{array}{l}\text { To what extent were conflicts resolved to your } \\
\text { satisfaction? }\end{array}$ \\
\hline & RE3 & $\begin{array}{l}\text { How soon were mutually agreeable solutions } \\
\text { reached when there was disagreement between you } \\
\text { and any other students? }\end{array}$ \\
\hline \multirow{5}{*}{$\begin{array}{l}\text { Group } \\
\text { Performance }\end{array}$} & PE1 & The efficiency of group operations \\
\hline & PE2 & The amount of work the group produced \\
\hline & PE3 & The quality of work the group produced \\
\hline & PE4 & The group's adherence to the schedule \\
\hline & PE5 & Effectiveness of the group members' interactions \\
\hline
\end{tabular}

TABLE II. DEMOGRAPHIC DATA FOR PARTICIPANTS

\begin{tabular}{|l|l|l|}
\hline \multirow{2}{*}{ Items } & \multicolumn{2}{|c|}{ Number of students } \\
\hline Grade & $2^{\text {nd }}$ year & $72(100 \%)$ \\
\hline \multirow{2}{*}{\begin{tabular}{l} 
Age \\
\multirow{2}{*}{$\begin{array}{l}\text { Previous } \\
\text { online courses }\end{array}$}
\end{tabular}} & $19 \sim 22$ & $72(100 \%)$ \\
\hline \multirow{3}{*}{$\begin{array}{l}\text { Previous } \\
\text { experience with } \\
\text { Wikipedia }\end{array}$} & NES & $17(23.6 \%)$ \\
\cline { 2 - 3 } & No experience & $55(76.4 \%)$ \\
\cline { 2 - 3 } & Only as audience & $28(38.9 \%)$ \\
\cline { 2 - 3 } & Administrator in Wikipedia & $25(34.7)$ \\
\hline \multirow{3}{*}{$\begin{array}{l}\text { Daily Internet } \\
\text { usage }\end{array}$} & $<=1$ hour & $9(12.5 \%)$ \\
\cline { 2 - 3 } & $>1$ hour, $<=3$ hours & $32(44.4 \%)$ \\
\cline { 2 - 3 } & $>=3$ hours & $27(37.5 \%)$ \\
\hline
\end{tabular}

Note: Information about gender is not collected due to anonymity
The two groups shared the same wiki database, which means they discussed on the same wiki article page in each round and the only difference between these two groups is whether the participants could see the new design or not. The three topics of discussion were all about computer ethics which could maximally arouse students' motivation to argue and exchange knowledge. The names of these topics were pirated software, computer related occupational disease and online gaming.

Immediately after each round of discussion, the participants were required to fill questionnaires about their usage experiences. The content of questionnaires can be found in table 1, and these questions are mainly adopted from [22] with minor modifications due to the research context (CSCL), however, the keywords and meanings of the original questions are remain unchanged. The analysis of survey data was conducted by using PLS method. PLS was selected since it did not need large sample size.

In order to better reflect the usefulness of new design, descriptive analysis of usage logs was presented. The quality of each group's contributions could not be easily judged since they worked on the same wiki articles. Instead, the number of contribution, and average length change of each edit were calculated to reflect the differences between two groups.

\section{RESEARCH METHOD}

\section{A. Survey study}

Seventy-two (72) undergraduate students were invited to participate in this lab experiment. Detailed information about the demographics of the sample can be seen in table 2. These students came from every department of a university, and they usually did not know each other. They were all enrolled in a university-level course.

Three rounds of online collaborative discussion were conducted and the ANOVA test results show that there is no significant difference on demographic data between two groups in each round. 208 valid questionnaires (100 from control group and 108 from experiment group) were gained. The response rate was $100 \%$ because the questionnaires were filled online and controlled by a program which did not allow missing questions. However, there were 8 invalid responses since the students asked for temporary absence due to personal issues.

The PLS analysis is conducted by using WarpPLS3.0, a partial least squares (PLS) software. PLS is selected because it does not require large sample. The number of questionnaires has met the requirement of PLS.

The measurement model is tested by examining: (1) individual item reliability, which is reflected by the loadings of the measures on their corresponding construct; (2) discriminate validity, which is mainly reflected by average variances extracted (AVE) of each construct; and (3) internal consistency, which is reflected by composite reliability and Cronbach's alpha coefficient of each construct. The result of measurement model test is shown in table 3 . 
TABLE III. RESULTS FOR THE MEASUREMENT MODEL

\begin{tabular}{|c|c|c|c|c|c|c|}
\hline Items & Mean & S.D. & $\begin{array}{l}\text { Factor } \\
\text { Loading } \\
\left(>0.5^{\mathrm{a}}\right)\end{array}$ & $\begin{array}{l}\text { C.A. } \\
\left(>0.7^{a}\right)\end{array}$ & $\begin{array}{l}\text { C.R. } \\
\left(>0.7^{\mathrm{a}}\right)\end{array}$ & $\begin{array}{l}\text { AVE } \\
\left(>0.5^{\mathrm{a}}\right)\end{array}$ \\
\hline $\begin{array}{l}\text { Conflict } \\
\text { Awareness }\end{array}$ & & & & 0.890 & 0.924 & 0.753 \\
\hline CA1 & 4.952 & 1.311 & 0.869 & & & \\
\hline CA2 & 5.394 & 1.195 & 0.895 & & & \\
\hline CA3 & 4.630 & 1.316 & 0.805 & & & \\
\hline CA4 & 5.231 & 1.226 & 0.898 & & & \\
\hline $\begin{array}{l}\text { Conflict } \\
\text { Resolution }\end{array}$ & & & & 0.835 & 0.901 & 0.753 \\
\hline RE1 & 5.197 & 1.268 & 0.867 & & & \\
\hline RE2 & 4.659 & 1.342 & 0.836 & & & \\
\hline RE3 & 5.111 & 1.275 & 0.898 & & & \\
\hline Participation & & & & 0.883 & 0.928 & 0.811 \\
\hline PA1 & 5.226 & 1.126 & 0.870 & & & \\
\hline PA2 & 4.894 & 1.215 & 0.917 & & & \\
\hline PA3 & 4.803 & 1.177 & 0.913 & & & \\
\hline $\begin{array}{l}\text { Personal } \\
\text { Influence }\end{array}$ & & & & 0.890 & 0.925 & 0.755 \\
\hline IN1 & 4.813 & 1.133 & 0.859 & & & \\
\hline IN2 & 4.995 & 1.024 & 0.933 & & & \\
\hline IN3 & 5.120 & 1.007 & 0.905 & & & \\
\hline IN4 & 4.813 & 1.100 & 0.771 & & & \\
\hline $\begin{array}{l}\text { Group } \\
\text { Performance }\end{array}$ & & & & 0.794 & 0.860 & 0.554 \\
\hline PE1 & 5.072 & 1.333 & 0.819 & & & \\
\hline PE2 & 4.389 & 1.162 & 0.638 & & & \\
\hline PE3 & 4.841 & 1.285 & 0.850 & & & \\
\hline PE4 & 4.745 & 1.440 & 0.746 & & & \\
\hline PE5 & 4.101 & 1.527 & 0.644 & & & \\
\hline
\end{tabular}

Note: a. Indicates threshold values of corresponding indices; S.D.: Standard deviation; C.A

Cronbach's alpha; C.R.: Composite reliability

For individual item reliability, the factor loading of about 0.7 or greater is recommended, whereas the value below 0.5 shows low trait variance [44]. Thus, the cut-off point is set at 0.5 . As table 3 shows that all factor loadings exceed 0.5 .

AVE is the average variance shared between a construct and its measure. All values of AVE shown in table 3 are greater than the recommended threshold $(0.5)$, suggesting that the latent constructs account for the majority of the variance in their indicators on average [45]. Furthermore, table 4 shows that the square roots of AVEs are all larger than corresponding correlations. Thus, discriminate validity is observed.

Composite reliability and Cronbach's alpha are both used for evaluating the internal consistency of the constructs, and 0.7 is recommended threshold for both indices. It can be seen from table 3 that all constructs have met the criterion.

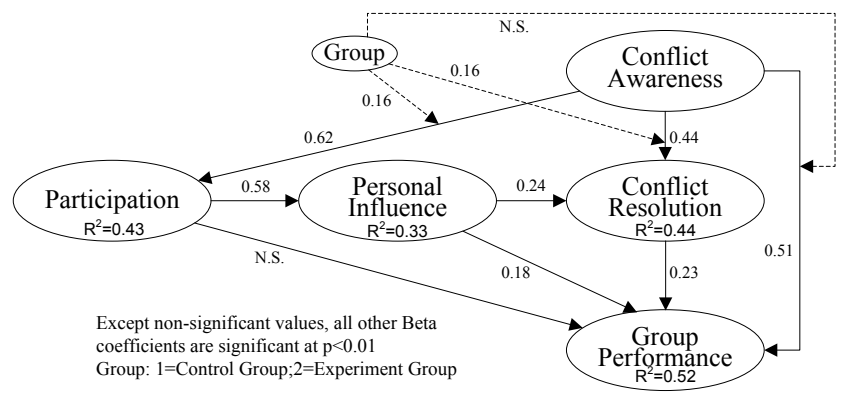

Figure 4. Result for the structural model
TABLE IV. RELIABILITY AND INTER-CONSTRUCT CORRELATIONS

\begin{tabular}{|l|c|c|c|c|c|c|c|}
\hline \multicolumn{1}{|c|}{ Constructs } & $\mathbf{1}$ & $\mathbf{2}$ & $\mathbf{3}$ & $\mathbf{4}$ & $\mathbf{5}$ & $\mathbf{6}$ & $\mathbf{7}$ \\
\hline 1.Participation & $\mathbf{0 . 9 0 0}$ & & & & & & \\
\hline 2.Personal Influence & 0.577 & $\mathbf{0 . 8 6 9}$ & & & & & \\
\hline 3.Conflict Resolution & 0.640 & 0.526 & $\mathbf{0 . 8 6 8}$ & & & & \\
\hline 4.Conflict Awareness & 0.640 & 0.588 & 0.605 & $\mathbf{0 . 8 6 8}$ & & & \\
\hline 5.Group Performance & 0.458 & 0.529 & 0.555 & 0.681 & $\mathbf{0 . 7 4 5}$ & & \\
\hline 6. Group & 0.031 & -0.105 & -0.002 & -0.057 & -0.030 & $\mathbf{1 . 0 0 0}$ & \\
\hline $\begin{array}{l}\text { 7. Group* Conflict } \\
\text { Awareness }\end{array}$ & 0.253 & 0.179 & 0.277 & 0.158 & 0.126 & 0.004 & $\mathbf{0 . 8 6 7}$ \\
\hline
\end{tabular}

Note: Square roots of AVE shown on diagonal; Except the italicized values, all correlations are

significant at $\mathrm{p}<0.001$ level

In the test for structural model, three model fitness indices are provided in WarpPLS, which are APC (average path coefficient), ARS (average R-squared) and AVIF (average variance inflation factor). Kock suggest that the significant levels for both the APC and ARS should be lower than 0.05, and the recommend value for the AVIF is lower than 5 [46]. In this study, the value of APC is 0.295 , and the value of ARS is 0.430 , with both values are significant at $\mathrm{p}<0.001$ level, suggesting a good model fit. The value of AVIF is 1.530, showing that there is no serious multi-collinearity among measurement items.

Fig. 4 shows the results for the structural model. The results suggest that participation has a positive influence on personal influence $(\beta=0.58, S . E=0.057)$, but the influence on group performance is insignificant, thus, $\mathrm{H} 1$ is supported but $\mathrm{H} 2$ is rejected. Personal influence is found to have positive effects on conflict resolution $(\beta=0.24, \mathrm{~S} . \mathrm{E}=0.065)$ and group performance $(\beta=0.18$, S.E $=0.078)$, thus, $\mathrm{H} 3$ and $\mathrm{H} 4$ are supported. The results also show that conflict resolution positively influence group performance $(\beta=0.23, \mathrm{~S} . \mathrm{E}=0.086)$ and H5 is supported. Conflict awareness is found to positively influence participation $(\beta=0.62, \mathrm{~S} . \mathrm{E}=0.050)$, conflict resolution $(\beta=0.44$, $\mathrm{S} . \mathrm{E}=0.057)$ and group performance $(\beta=0.51, \mathrm{~S} . \mathrm{E}=0.088)$, thus $\mathrm{H} 6, \mathrm{H} 7$ and $\mathrm{H} 8$ are supported. Moreover, the percentage of the variance explained $\left(\mathrm{R}^{2}\right)$ of participation, influence, conflict resolution and group performance are $43 \%, 33 \%, 44 \%$ and $52 \%$, respectively.

For moderating effects, the PLS results shows that the moderator (group) can significantly moderate relationships between participation and conflict awareness $(\beta=0.16$, S.E $=0.060)$, conflict awareness and resolution $(\beta=0.16$, $\mathrm{S} . \mathrm{E}=0.069$ ), but fail in moderating relationship between conflict awareness and group performance, thus, H9 is partially supported.

\section{B. Descriptive analysis of usage logs}

The numbers of contributions in three rounds of discussion were 642,461 and 628 . The lengths of final versions of discussion articles, measured by number of characters, were 77762,89304 and 81207. 
TABLE V. STATISTICS OF USAGE DATA

\begin{tabular}{|l|c|c|c|c|c|c|}
\hline & \multicolumn{3}{|c|}{ Experiment Group } & \multicolumn{3}{c|}{ Control Group } \\
\hline Round & 1 & 2 & 3 & 1 & 2 & 3 \\
\hline $\begin{array}{l}\text { Number of } \\
\text { Contributions }\end{array}$ & 415 & 251 & 384 & 227 & 210 & 244 \\
\hline $\begin{array}{l}\text { Average change of each } \\
\text { edit (in characters) }\end{array}$ & 210.2 & 330.5 & 247.5 & 189.7 & 116.9 & 210.1 \\
\hline
\end{tabular}

As it can be seen from table 5, students in experimental group contribute much more times than students in control group. And for each edit, students in experimental group contribute more content. In all, the statistics of usage logs shows that the new design can increase participants' contribution activities.

\section{CONCLUSION AND DISCUSSION}

Through the implementation of collaborative learning on wiki, this study has at least two contributions. First, it highlights the importance of conflict in collaborative work and figures out the pair-wise relationships among relevant factors. Conflict awareness is found to positively influence participation, conflict resolution and group performance. Meanwhile, participation is found to positively influence personal influence. However, the relationship between participation and group performance is insignificant, this result is not in agreement with Robey's model of conflict, but it is, to some extent, in consistent with other studies [47]. Furthermore personal influence positively affects conflict resolution and group performance, and conflict resolution positively affects group performance. These results are almost consistent with prior studies (e.g. [22]) and the authors' previous work [21], reflecting that the findings are stable across various contexts and samples. Second, in order to utilize conflict, this study puts forward three new functions, including paragraph-based history list with text comparison, visualization of conflict network and content ownership. These functions give users detailed evolution history of the content, points out arguable pieces of content, shows hidden conflict network, and fulfill the needs of psychological ownership. The results have supported the usefulness of the new design, indicating that the functions can significantly enhance the influence of conflict awareness on participation and conflict resolution. However, one of the results in the previous work [21], which shows that the design could significantly reduce the influence of conflict awareness on group performance, cannot be found in this study.

One point should be mentioned that, with the help of students' anonymously participation and characteristics of wiki, the authors are able to limit the scope of conflict to task conflict, develop and verify new design based on conflict. Thus the results are unable to explain the consequences of other types of conflict (relationship conflict and process conflict).

This study also has some limitations. First, it only uses undergraduate students as sample. Although undergraduate students represent the majority of users in collaborative learning, disregarding other kinds of user (e.g. middle school student) can cause variance in the final result. Second, the new design still needs to be improved. While advanced visualization technologies (e.g. social network) have been widely developed in many studies (e.g. [48]), this study only applies textcomparison algorithm and basic social network visualization method. Any future improvement in the design will affect the students' motivation to participate, which may yield different result. Moreover, current version of this design is implemented by using external programs. Future deployment may be limited unless it can be re-programmed as wiki plugin. Third, this study jointly measures three new functions as a whole, since they are represented in one dialog. Future studies are suggested to investigate the effects of these three functions separately.

For researchers, first, it is suggested to include more variables in future study, for example, gender, personality and task type. Since male and female students have different ways of using e-learning systems [49], the perception of design in this study may not be same across gender. Moreover, due to different backgrounds (e.g. socio-economic status, age), students may have different personalities, such as conscientiousness, openness, extraversion, agreeableness and neuroticism (Big Five model) [50]. The reactions to the design may also be different across personalities. For example, students who with openness personality may be very glad to see the changes of his content, while this design may enlarge the feeling of infringement by student who with neuroticism personality. Second, the insignificant relationship between participation and group performance suggests that deeper investigation should be conducted, especially task type. Comparing to routine task (e.g. collaboratively translation), complex task (low task routineness) for students requires more cooperation activities and higher knowledge threshold. Such different types of task may yield entirely different model results. And third, since there is different result between this study (three functions) and previous work (two functions, no network visualization) [21] on how the design affects the influence of conflict awareness on group performance, future work will be conducted to find out whether the network visualization cause this difference or not.

In practice, trust and reciprocity has been used to motivate users' participation in designing e-learning system [48]. The new design in this study offers a relative new idea to motivate users to participate by using conflict. Conflict management is very important because collaborative work is naturally a kind of negotiation among participants and cannot get rid of conflict. We suggest in the future, more human-centered functions should be developed to display conflict, for example, using different background colors to display degrees of conflict, and using dialogs to notify user which parts of content are the most conflicting and need attention.

\section{REFERENCES}

[1] K. Wu, Q. Zhu, J. Vassileva, and Y. Zhao, Does confict matter in the success of mass collaboration? Investigating antecedents and consequence of conflict in wikipedia, Chinese Journal of Library and Information Science, vol. 5, pp. 34-50, 2012.

[2] R. F. Zammuto, T. L. Griffith, A. Majchrzak, D. J. Dougherty, and S. Faraj, Information technology and the changing fabric of organization, Organization Science, vol. 18, pp. 749-762, 2007.

[3] D. Tapscott and A. D. Williams, Wikinomics: How mass collaboration changes everything. New York: Penguin Group, 2008.

[4] K. Crowston, The motivational arc of massive virtual collaboration, presented at the Proceedings of the IFIP WG 9.5 Working Conference 
on Virtuality and Society: Massive Virtual Communities, Lüneberg, Germany, 2008.

[5] J. Giles, Internet encyclopaedias go head to head, Nature, vol. 438, pp. 900-901, 2005.

[6] L. A. Adamic, J. Zhang, E. Bakshy, and M. S. Ackerman, Knowledge sharing and yahoo answers: Everyone knows something, presented at the Proceedings of the 17th international conference on World Wide Web, Beijing, China, 2008.

[7] E. H. Chi, Augmented social cognition: Using social web technology to enhance the ability of groups to remember, think, and reason, presented at the Proceedings of the 35th SIGMOD international conference on Management of data, Providence, Rhode Island, USA, 2009.

[8] A. Kittur, B. Suh, B. A. Pendleton, and E. H. Chi, He says, she says: Conflict and coordination in wikipedia, presented at the Proceedings of the SIGCHI conference on Human factors in computing systems, San Jose, California, USA, 2007.

[9] S. Bongwon, E. H. Chi, B. A. Pendleton, and A. Kittur, Us vs. Them: Understanding social dynamics in wikipedia with revert graph visualizations, in Visual Analytics Science and Technology, 2007. VAST 2007. IEEE Symposium on, 2007, pp. 163-170.

[10] S. Koushik, J. Birkinshaw, and S. Crainer, Using web 2.0 to create management 2.0, Business Strategy Review, vol. 20, pp. 20-23, 2009.

[11] J. Moskaliuk, J. Kimmerle, and U. Cress, Collaborative knowledge building with wikis: The impact of redundancy and polarity, Computers \& Education, vol. 58, pp. 1049-1057, 2012.

[12] M. Raman, T. Ryan, and L. Olfman, Designing knowledge management systems for teaching and learning with wiki technology, Journal of Information Systems Education, vol. 16, pp. 311-321, 2005.

[13] P. Pusey and G. Meiselwitz, Heuristics for implementation of wiki technology in higher education learning, in Online communities. vol. 5621, A. Ozok and P. Zaphiris, Eds., ed: Springer Berlin / Heidelberg, 2009, pp. 507-514.

[14] S. Reinhold, Wikitrails: Augmenting wiki structure for collaborative, interdisciplinary learning, presented at the Proceedings of the 2006 international symposium on Wikis, Odense, Denmark, 2006.

[15] A. Forte and A. Bruckman, Constructing text:: Wiki as a toolkit for (collaborative?) learning, presented at the Proceedings of the 2007 international symposium on Wikis, Montreal, Quebec, Canada, 2007.

[16] A. Forte and A. Bruckman, From wikipedia to the classroom: Exploring online publication and learning, presented at the Proceedings of the 7th international conference on Learning sciences, Bloomington, Indiana, 2006.

[17] A. Lund and O. Smørdal, Is there a space for the teacher in a wiki?, presented at the Proceedings of the 2006 international symposium on Wikis, Odense, Denmark, 2006.

[18] B. T. Adler, et al., Assigning trust to wikipedia content, presented at the Proceedings of the 4th International Symposium on Wikis, Porto, Portugal, 2008.

[19] I. Blau and A. Caspi, What type of collaboration helps? Psychological ownership, perceived learning and outcome quality of collaboration using google docs, presented at the Proceedings of the Chais conference on instructional technologies research 2009: Learning in the technological era, Raanana, 2009.

[20] H. Zeng, M. A. Alhossaini, L. Ding, R. Fikes, and D. L. Mcguinness, Computing trust from revision history, presented at the Proceedings of the 2006 International Conference on Privacy, Security and Trust: Bridge the Gap Between PST Technologies and Business Services, Markham, Ontario, Canada, 2006.

[21] K. Wu, J. Vassileva, Q. Zhu, Y. Zhao, and X. Sun, Motivating wikibased group collaboration: The role of task conflict, unpublished.

[22] D. Robey, L. A. Smith, and L. R. Vijayasarathy, Perceptions of conflict and success in information systems development projects, Journal of Management Information System, vol. 10, pp. 123-139, 1993.

[23] S. Wheeler, P. Yeomans, and D. Wheeler, The good, the bad and the wiki: Evaluating student-generated content for collaborative learning, British Journal of Educational Technology, vol. 39, pp. 987-995, 2008.

[24] K. E. Boulding, Conflict and defense: A general theory. USA: University Press of America, 1988.
[25] S. M. Schmidt and T. A. Kochan, Conflict: Toward conceptual clarity, Administrative Science Quarterly, vol. 17, pp. 359-370, 1972.

[26] K. A. Jehn and E. A. Mannix, The dynamic nature of conflict: A longitudinal study of intragroup conflict and group performance, The Academy of Management Journal, vol. 44, pp. 238-251, 2001.

[27] C. B. Gibson and S. G. Cohen, Virtual teams that work: Creating conditions for virtual team effectiveness: Jossey-Bass, 2003.

[28] T. L. Simons and R. S. Peterson, Task conflict and relationship conflict in top management teams: The pivotal role of intragroup trust, Journal of Applied Psychology, vol. 85, pp. 102-111, 2000.

[29] O. Arazy, O. Nov, R. Patterson, and L. Yeo, Information quality in wikipedia: The effects of group composition and task conflict, Journal of Management Information Systems, vol. 27, pp. 71-98, Spring2011 2011.

[30] S. P. Robbins, Managing organizational conflict:A nontraditional approach. Englewood Cliffs, New Jersey: Prentice Hall, 1974.

[31] G. C. Kane and R. G. Fichman, The shoemaker's children: Using wikis for information systems teaching, research, and publication, MIS Q., vol. 33, pp. 1-17, 2009.

[32] A. Kittur, E. H. Chi, and B. Suh, What's in wikipedia?: Mapping topics and conflict using socially annotated category structure, presented the Proceedings of the 27th international conference on Human factors in computing systems, Boston, MA, USA, 2009.

[33] F. B. Viegas, M. Wattenberg, and K. Dave, Studying cooperation and conflict between authors with history flow visualizations, presented at the Proceedings of the SIGCHI conference on Human factors in computing systems, Vienna, Austria, 2004.

[34] M. Wattenberg, F. Viégas, and K. Hollenbach, Visualizing activity on wikipedia with chromograms, in Human-computer interaction - interact 2007. vol. 4663, C. Baranauskas, et al., Eds., ed: Springer Berlin / Heidelberg, 2007, pp. 272-287.

[35] M. D. Ekstrand and J. T. Riedl, Rv you're dumb: Identifying discarded work in wiki article history, presented at the Proceedings of the 5th International Symposium on Wikis and Open Collaboration, Orlando, Florida, 2009.

[36] D. Robey, D. L. Farrow, and C. R. Franz, Group process and conflict in system development, Management Science, vol. 35, pp. 1172-1191, 1989.

[37] L. Lipponen, Exploring foundations for computer-supported collaborative learning, presented at the Proceedings of the Conference on Computer Support for Collaborative Learning: Foundations for a CSCL Community, Boulder, Colorado, 2002.

[38] P. N. David, S. J. D. B. Ryan, D. B. C. Ro, P. R. Carolyn, and C. Yue, Detecting and understanding the impact of cognitive and interpersonal conflict in computer supported collaborative learning environments, presented at the International Conference on Educational Data Mining, Cordoba, Spain, 2009.

[39] L. H. Chan and C.-H. Chen, Conflict from teamwork in project-based collaborative learning, Performance Improvement, vol. 49, pp. 23-28, 2010 .

[40] A. Ardichvili, V. Page, and T. Wentling, Motivation and barriers to participation in virtual knowledge-sharing communities of practice, Knowledge Management, vol. 7, pp. 64-77, 2003.

[41] A. Semadar, G. Robins, and G. R. Ferris, Comparing the validity of multiple social effectiveness constructs in the prediction of managerial job performance, Journal of Organizational Behavior, vol. 27, pp. 443461, 2006.

[42] F. M. Harper, S. X. Li, Y. Chen, and J. A. Konstan, Social comparisons to motivate contributions to an online community, presented at the Proceedings of the 2nd international conference on Persuasive technology, Palo Alto, CA, USA, 2007.

[43] L. Festinger, A theory of cognitive dissonance: Stanford University Press, 1957.

[44] R. P. Bagozzi, Measurement and meaning in information systems and organizational research: Methodological and philosophical foundations, MIS Quarterly, vol. 35, pp. 261-292, 2011.

[45] S. B. Mackenzie, P. M. Podsakoff, and N. P. Podsakoff, Construct measurement and validation procedures in mis and behavioral research: 
Integrating new and existing techniques, MIS Quarterly, vol. 35, pp. 293-A5, 2011.

[46] N. Kock, Using warppls in e-collaboration studies: Descriptive statistics, settings, and key analysis results, International Journal of eCollaboration, vol. 7, pp. 1-18, 2011.

[47] J. Davies and M. Graff, Performance in e-learning: Online participation and student grades, British Journal of Educational Technology, vol. 36, pp. 657-663, 2005.
[48] J. Vassileva and L. Sun, Using community visualization to stimulate participation in online communities, e-Service Journal, vol. 6, pp. 3-39, Fall2007 2007.

[49] C.-S. Ong and J.-Y. Lai, Gender differences in perceptions and relationships among dominants of e-learning acceptance, Computers in Human Behavior, vol. 22, pp. 816-829, 2006.

[50] M. R. Barrick and M. K. Mount, The big five personality dimensions and job performance: A meta-analysis, Personnel Psychology, vol. 44, pp. 1-26, 1991. 